\title{
Malnutrition and associated factors among adults starting on antiretroviral therapy at PASADA Hospital in Temeke District, Tanzania
}

\author{
TITUS K. KABALIMU1*, EDSON SUNGWA² and WARLES C. LWABUKUNA ${ }^{3}$ \\ ${ }^{1}$ Department of Community Medicine, Faculty of Medicine, Hubert Kairuki Memorial University, Dar es Salaam, \\ Tanzania \\ ${ }^{2}$ Department of Fundamentals of Nursing, Faculty of Nursing, Hubert Kairuki Memorial University, Dar es Salaam, \\ Tanzania \\ ${ }^{3}$ Department of Internal Medicine, Faculty of Medicine, Hubert Kairuki Memorial University, Dar es Salaam, Tanzania
}

\begin{abstract}
Background: Malnutrition is known to play a significant role in HIV/AIDS progression. Severe malnutrition has been previously found to be associated with early mortality among people living with HIV/AIDS (PLHIV) undergoing anti-retroviral therapy (ART) in Sub-Saharan Africa. The objective of this study was to determine the prevalence and factors associated with malnutrition among adult PLHIV attending care and treatment centre (CTC) in Temeke District, Tanzania.

Methods: The cross-sectional descriptive study involved consecutive eligible patients attending the CTC for initiating in ART, between January and April, 2014. All participants who agreed to sign a consent form were enrolled. The participants had undergone baseline workup for ART initiation (by CTC), which included blood tests for liver and renal function tests, and CD4+ cell count, using calibrated instruments and standard techniques. In all patients the weight and height were measured to calculate the body mass index (BMI), denoting the nutritional status. This parameter was recorded in the study instrument together with the CD4+ count for each patient. A structured questionnaire was used to obtain more information, namely demographic and lifestyle data.

Results: A total of 125 patients were included in this study. The prevalence of malnutrition among participants was $19.4 \%$. Those with severe malnutrition comprised of $9 \%$. Significant association was noted between malnutrition and irregular income $(\mathrm{OR}=3.8, \mathrm{Cl}: 1.2-11.5)$ and also inability to get at least two meals a day $(\mathrm{OR}=$ 3.4, Cl: 1.2-9.2). Severe malnutrition was significantly associated with the CD4+ counts of $<200$ cells $/ \mathrm{mm}$ (OR $=7.6 ; \mathrm{Cl}: 1.7-34.6)$.

Conclusion: About $19 \%$ of participants were malnourished at the time of initiation of ART and among them $9 \%$ were severely malnourished. The most important risks for malnutrition were found to be irregular income and inability to get adequate feeding. This calls for routine nutritional assessment at CTCs prior to initiation of ART so as to identify those who need immediate intervention, including those with severe malnutrition.

Keywords: malnutrition, HIV/AIDS, anti-retroviral therapy, Tanzania
\end{abstract}

\section{Introduction}

Adequate nutrition, which is best achieved through consumption of a balanced healthy diet, is vital for health and survival of all individuals regardless of HIV status. In the case of HIV infection there occurs a rapid replication of the virus, requiring larger amounts of energy and nutrients which are actually taken from the host's body because the virus depends entirely on the host for survival (WHO, 2003). The HIV infection causes increased requirement for nutrients by 20 to $30 \%$, but, at the same time exacerbates reduced food intake through hyperpyrexia, anorexia and thus leading to malnutrition (WHO, 2003). Malnutrition, in turn, leads to impairment of the immune system and a rapid progression of HIV infection to AIDS. Therefore, it becomes clear that malnutrition and HIV are related and aggravate one another in a vicious cycle (MoHSW, 2012).

\footnotetext{
*Correspondence E-mail: titus.kabalimu@hkmu.ac.tz; kabalimutitus@gmail.com
} 
Adult malnutrition, as exemplified by wasting is defined as a body mass index (BMI) of $<18.5$ $\mathrm{kg} / \mathrm{m}^{2}$ in adults (WHO, 2003; Koethe \& Heimburger, 2010). Despite confounding factors in the African setting the BMI indicator has proved to be the most reliable measure of wasting in adults. Among adults with advanced HIV infection in sub-Saharan Africa the magnitude of malnutrition (BMI-below 18.5) was shown to be between 10 and 30\%, where social factors like income, employment, inadequate food intake, and sanitation were implicated as risk factors (Niyongabo et al., 1999; Dannhauser et al., 1999; Uthman, 2008; Hailemariam et al., 2013). The prevalence of malnutrition (BMI<18.5), among PLHIV who are receiving ART in Tanzania has been reported to be $18.4 \%$ and was mainly associated with the pattern of food intake (Ritte \& Kessy, 2012).

On the other hand, severe malnutrition is associated with early mortality among People Living with HIV/AIDS (PLHIV), initiating on ART, where a low BMI was pointed out as a strong independent factor of that mortality. Also pointed out is that increasing grades of malnutrition plus decreasing $\mathrm{CD} 4+$ cell count accelerate the risk of mortality. Meanwhile, weight gain, after the initiation of ART is shown to be strongly associated with improved survival (Koethe \& Heimburger 2009; Koethe et al., 2010; Liu et al., 2011). Malnutrition has bad effects on the progress of disease in PLHIV, as is indicated in the above mentioned studies. Since information about the status in Tanzania is limited, this study was carried out to assess the prevalence of malnutrition and associated factors among PLHIV who are starting on ART.

\section{Materials and Methods}

\section{Study area}

The study was carried out in Temeke District in Dar es Salaam, Tanzania. Temeke has several approved Care and Treatment (CTC) Centres for HIV/AIDS management. For the purposes of this study only PASADA Hospital was purposively selected due to the fact this place also provides palliative care in Temeke district and that the majority of patients needing the CTC services receive them at this hospital. PASADA is an acronym for Pastoral Activities and Services for people with AIDS in Dar es Salaam Archdiocese. This is mainly a CTC hospital which provides holistic care to PLHIV including the Prevention of mother-to-child transmission of HIV (PMCTC) issues. PASADA takes care of about 3,000 adults and 6,000 children monthly. The CTC turnover per day is about 65 patients.

\section{Study design and population}

An exploratory descriptive survey involving patients attending the CTC at PASADA hospital between January and April, 2014 was conducted. All consecutive patients reporting to PASADA and having been eligible for the initiation of ART were considered and enrolled, after their consenting. A purposeful sampling was employed whereby all eligible, consecutive patients attending CTC at the time of this study plus those who had been recruited two weeks back and coming for more drugs were recruited. The inclusion criteria were male or female $>18$ years; confirmed CD4+ count $<200 / \mathrm{mm}^{3}$ or WHO stage IV; and eligible to start on ART and no history of taking concurrent or alternative medicine. The exclusion criteria were life threatening opportunistic infections, treatment with immune modulating medications and refusal to sign informed consent form.

This study depended on the baseline workup for ART initiation done by the CTC, in accordance with the National Guidelines for Care and Treatment of PLHIV- Tanzania. The workup included blood tests for liver function tests (LFTs), renal function tests (RFTs) and CD4+ cell count, using calibrated instruments and standard techniques. In all patients the weight and height were measured to calculate the body mass index (BMI), which was recorded in the study instrument together with the CD4+ count for each patient. A structured questionnaire was used to obtain more information, namely demographic, and lifestyle data. The sample size was calculated by adopting the fact that wasting with 
the body mass index (BMI) of $<18.5$ in adults with advanced HIV infection is $20-30 \%$. A maximum likely error of $7 \%$ with significance level of $5 \%$ were used. Therefore the minimum sample size was 125 clients.

\section{Data collection}

Baseline data on demographic and social characteristics such as age, sex, marital status, occupation, educational level, income, and meal frequency were obtained from participants by using a researcher administered questionnaire. For each participant weight and height were measured. Height was measured when the patient was standing erect against a wall marked with measurement, while weight was measured on a standing scale. The body-mass index for each patient was calculated as weight $(\mathrm{kg}) /$ height $(\mathrm{m})^{2}$. Information on the $\mathrm{CD} 4+$ count was obtained from available data in the patients' files.

\section{Data analysis}

Collected data were subsequently pre-coded and entered into the computer using Microsoft Excel Spreadsheet before exporting to SPSS version 20 for analysis. Information was summarized by using frequency tables and cross tabulations. The chi-squared test was used to establish association between the dependent variable, namely malnutrition and independent variables.

\section{Ethical considerations}

The research protocol was submitted to Hubert Kairuki Memorial University's Ethics Review Committee, which granted the ethical clearance, after review and approval. Permission to conduct the study at PASADA was sought from the Medical Director of the hospital. Prior to taking part in the study participants were provided information about the purposes of the study plus expected outcomes and potential benefits. Respondents who agreed were asked for consent by signing the consent form, before administering the questionnaire and taking measurements of weight and height.

\section{Results}

A total of 125 patients were included in this study. Majority of them were aged between 30-39 years. A comparison of the younger groups with older people shows that $67 \%$ of the participants were aged between 29 and 39 years. Majority (80\%) were females (Table 1 ).

Table 1: Socio-demographic characteristics of the study population

\begin{tabular}{llll}
\hline Variable & Characteristics & Number & Percentage \\
\hline Sex & Female & 100 & 80 \\
Age (years) & Male & 25 & 20 \\
& $20-29$ & 21 & 16.8 \\
& $30-39$ & 55 & 44 \\
& $40-49$ & 33 & 26.4 \\
Marital status & $50-59$ & 9 & 7.2 \\
& $60+$ & 7 & 5.6 \\
& Married & 38 & 30.4 \\
Occupation & Single & 46 & 36.8 \\
& Divorced & 21 & 16.8 \\
Education level & Widowed & 20 & 16 \\
& Unemployed & 36 & 28.8 \\
& Business & 72 & 57.6 \\
& Employed & 17 & 13.6 \\
& Primary & 99 & 79.2
\end{tabular}




\begin{tabular}{llcl} 
& Tertiary & 2 & 1.6 \\
Residence & Rural & 54 & 43.2 \\
Income & Urban & 71 & 56.8 \\
& Irregular & 59 & 47.2 \\
Meal frequency & Regular & 66 & 52.8 \\
Haemoglobin level & $<2$ per day & 29 & 23.2 \\
& $3+$ per day & 96 & 79.8 \\
& Severe anaemia & 14 & 11.2 \\
& Moderate & 78 & 62.4 \\
\hline
\end{tabular}

\section{Nutritional status of research participants}

The overall prevalence of malnutrition in this study was 19.2\% (24/125), while severe malnutrition, BMI $<16$ was $8.8 \%$ (11/125). Participants with underweight (BMI= $16-18.5)$ were $10.4 \%$ (13/125) while the majority, $80.8 \%$ (101/125) had normal nutrition (Table 2).

Table 2: Participants by nutritional status (body mass index, BMI)

\begin{tabular}{llll}
\hline Nutritional status & BMI & Number of patients & Percentage \\
\hline Severe Malnutrition & $<16.0$ & 11 & 8.8 \\
Under weight & $16.0-18.5$ & 13 & 10.4 \\
Normal weight & $18.5-25.0$ & 101 & 80.8 \\
\hline
\end{tabular}

Table 3 indicates that the proportion of those with malnutrition among males was $43 \%$ compared to $14 \%$ among females $\left(X^{2}=10.055, p=0.02\right)$, meaning that the difference between males and females with regard to malnutrition was statistically significant. This means, males were more likely to be malnourished than females $(p<0.05)$. However, the proportions of malnutrition between different age groups were not statistically significant $\left(\chi^{2}=3.903, p=>0.05\right)$. Irregular income showed a significant association with malnutrition $\left(\chi^{2}=6.234, p<0.05\right)$ and so was the number of meals per day being less than $3\left(\chi^{2}=6.605, p<0.05\right)$.

Table 3: Nutritional status in relation to age, sex, income, meal frequency, CD4 count and anaemia

\begin{tabular}{|c|c|c|c|c|c|}
\hline \multirow[t]{2}{*}{ Variable } & \multirow[t]{2}{*}{ Variable category } & \multicolumn{2}{|c|}{ Nutritional Status } & \multirow[t]{2}{*}{$x^{2}$} & \multirow[t]{2}{*}{ P-value } \\
\hline & & $\begin{array}{l}\text { Normal: } \\
\text { BMI=18.5-25 }\end{array}$ & $\begin{array}{l}\text { Underweight } \\
\mathrm{BMI}=16-18.5\end{array}$ & & \\
\hline \multirow[t]{2}{*}{ Sex } & Male & 57.1 & 42.9 & 10.055 & 0.002 \\
\hline & Female & 86.5 & $13 \cdot 5$ & & \\
\hline \multirow[t]{5}{*}{ Age } & $20-29$ & 68.9 & 31.8 & 3.903 & 0.419 \\
\hline & $30-39$ & 81.5 & 18.5 & & \\
\hline & $40-49$ & 87.9 & 12.1 & & \\
\hline & $50-59$ & 88.9 & 11.1 & & \\
\hline & $60+$ & 85.7 & $14 \cdot 3$ & & \\
\hline \multirow[t]{2}{*}{ Income } & Regular & 90.3 & 9.7 & 6.234 & 0.013 \\
\hline & Irregular & 73.0 & 27.0 & & \\
\hline \multirow[t]{2}{*}{ Meal frequency } & 3+ per day & 86.8 & 13.2 & 6.056 & 0.02 \\
\hline & $<3+$ per day & 67.6 & 32.4 & & \\
\hline \multirow[t]{4}{*}{ CD4 Count } & $<100$ & 56.0 & 44.0 & 20.033 & $<0.001$ \\
\hline & 100-199 & 74.2 & 25.8 & & \\
\hline & 200-299 & 97.5 & 2.5 & & \\
\hline & $300+$ & 89.7 & 10.3 & & \\
\hline \multirow[t]{2}{*}{ Anaemia } & Normal & 90.9 & 9.1 & 2.843 & 0.241 \\
\hline & Moderate Anaemia & 79.0 & 21.0 & & \\
\hline
\end{tabular}


After controlling for all important independent variables it was established that only irregular income, $(\mathrm{OR}=3.8(\mathrm{Cl} 1.2-11.5)$ and the number of meals per day $(\mathrm{OR}=3.4(\mathrm{Cl}$ 1.2-9.2) had a significant association with malnutrition, as is indicated in Table 4 below.

Table 4: Detailed association between Nutritional status and other parameters

\begin{tabular}{|c|c|c|c|c|c|c|c|}
\hline \multirow[t]{2}{*}{ Variable } & \multirow[t]{2}{*}{ Variable category } & \multicolumn{3}{|c|}{ Crude } & \multicolumn{3}{|c|}{ Adjusted } \\
\hline & & OR & $95 \% \mathrm{Cl}$ & p-value & OR & $95 \% \mathrm{Cl}$ & P-value \\
\hline \multirow[t]{2}{*}{ Sex } & Female & 1 & & & 1 & & \\
\hline & Male & 4.8 & $1.7-13 \cdot 5$ & 0.003 & 5.1 & $1.7-14.7$ & 0.003 \\
\hline \multirow[t]{5}{*}{ Age } & $20-29$ & 1 & & & 1 & & \\
\hline & $30-39$ & 0.48 & $0.2-1.5$ & 0.212 & 0.5 & $0.2-1.6$ & 0.265 \\
\hline & $40-49$ & 0.29 & $0.1-1.2$ & 0.083 & 0.2 & $0.1-1.1$ & 0.550 \\
\hline & $50-59$ & 0.26 & $0.1-2.5$ & 0.254 & 0.1 & $0.1-1.8$ & 0.140 \\
\hline & $60+$ & 0.35 & $0.1-3.5$ & 0.380 & 0.2 & $0.1-3.1$ & 0.279 \\
\hline \multirow[t]{2}{*}{ Income } & Regular & 1 & & & 1 & & \\
\hline & Irregular & 3.5 & $1.2-9 \cdot 4$ & 0.016 & 3.8 & $1.2-11.5$ & 0.017 \\
\hline \multirow{2}{*}{$\begin{array}{l}\text { Meal } \\
\text { frequency }\end{array}$} & $3+$ per day & 1 & & & 1 & & \\
\hline & $<3+$ per day & 3.1 & $1.2-8.0$ & 0.017 & 3.4 & $1.2-9.2$ & 0.015 \\
\hline \multirow[t]{4}{*}{ CD4 Count } & $300+$ & 1 & & & 1 & & \\
\hline & 200-299 & 0.2 & $0.2-2.2$ & 0.203 & 0.24 & $0.1-2.5$ & 0.234 \\
\hline & 100-199 & 3.0 & $0.7-12.7$ & 0.133 & 3.7 & $0.8-16.4$ & 0.083 \\
\hline & $<100$ & 6.8 & $1.6-28.5$ & 0.009 & 7.6 & $1.7-34.6$ & 0.008 \\
\hline \multirow[t]{3}{*}{ Anaemia } & Normal & 1 & & & 1 & & \\
\hline & Moderate Anaemia & 2.6 & $0.7-9.7$ & 0.141 & 2.3 & $0.6-8.8$ & 0.203 \\
\hline & Severe Anaemia & 3.7 & $0.6-22.2$ & 0.146 & 3.1 & $0.5-18.8$ & 0.220 \\
\hline
\end{tabular}

Table 5 (a): Distribution of CD4+ count among participants with and without malnutrition: 4 categories

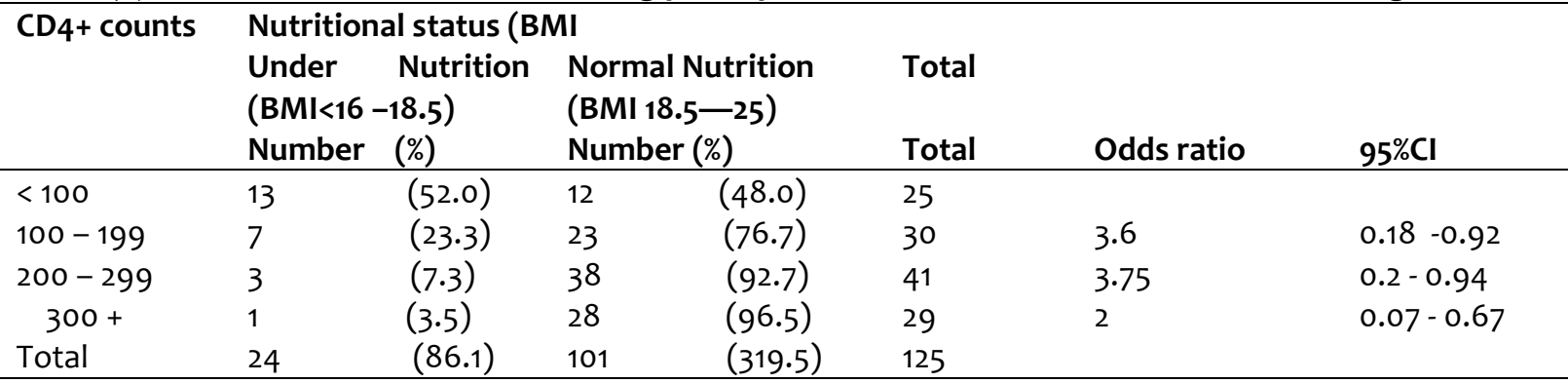

Table 5(b) Distribution of CD4+ count among participants with and without malnutrition: two categories

\begin{tabular}{|c|c|c|c|c|c|c|}
\hline \multirow[t]{2}{*}{ CD4+ counts } & \multicolumn{2}{|c|}{$\begin{array}{l}\text { Under Nutrition } \\
(\mathrm{BMI}<16-18.5)\end{array}$} & \multicolumn{2}{|c|}{$\begin{array}{l}\text { Normal Nutrition } \\
\text { (BMI 18.5-25) }\end{array}$} & \multicolumn{2}{|l|}{ Total } \\
\hline & Number & Percentage \% & Number & Percentage \% & Total & Percentage \% \\
\hline$<200$ & 20 & $(62.5)$ & 12 & (37.5) & 32 & $(100)$ \\
\hline $200-299$ & 4 & $(4.3)$ & 89 & $(95.7)$ & 93 & $(100)$ \\
\hline Total & 24 & & 101 & & 125 & 100 \\
\hline
\end{tabular}

Odds Ratio $=37.08(\mathrm{Cl}=0.79-28.99)$

Table 5a shows among people with CD4 count below 100, the proportion of malnourished people was $52 \%$ but as the cell count reads between 200 and 300 the proportion of malnutrition drops to $3.5 \%$ 
indicating that people with $\mathrm{CD} 4<100$ were more likely to have under nutrition than their counterparts with the CD4 count of $>200$. Recategorising the distribution of CD 4 count among participants into a two by two table (table 5b) shows also that the proportion of people with malnutrition was higher (62.5\%) among those with low CD4 counts (CD4<200) than in those with CD4 $>200(4.3 \%)$ but the difference was not statistically significant, $\mathrm{OR}=37.08,95 \% \mathrm{Cl}=0.79 ; 28.99$.

\section{Discussion}

In this study the overall prevalence of malnutrition was 19.2\% while severe malnutrition was about $9 \%$. The results were almost consistent with those obtained from a similar study in Tanzania: 18.4\% (Ritte \& Kessy, 2012). The results did not differ much from those in other low-and-middle income countries including Kenya (23.6\%), Nepal (19.9\%) and Ethiopia (23.2\%) (Kuria, 2008; Thapa et al., 2015; Mitiku et al., 2016). These results however, differ from analyses done in 11 Sub-Saharan countries where the prevalence was lower (Uthman, 2008). Similarly, studies in referral hospitals in Ethiopia and Nigeria, reported relatively lower prevalence rates (5.8-12.3\%) (Hailemariam et al., 2013; Folasire et al., 2015). However, severe malnutrition, which is clearly highlighted by this study was not addressed in those previous studies.

Another major finding of this study was the demographic characteristic of study participants which showed that among all participants two thirds were young. The age groups (20-40years) involved as PLHIV in this study are similar to those found in other studies in Tanzania and Ethiopia (Semali et al., 2011; Ritte \& Kessy, 2012). Attendees to CTCs as noted in this study and in several others are predominantly young women between 20 and 39 years (Uthman, 2008; Semali et. al., 2011; Ritte \& Kessy, 2012). For Tanzania, this could probably be explained by the community-based HIV/AIDS surveys which reveal that the prevalence of HIV infection is highest among females aged 25 and 34 years compared to males in the same age group (THMIS, 2013). These figures from surveys could probably explain the highest proportion of females attending the CTCS as observed in this study.

This study showed that there was a statistically significant association between malnutrition and the lack of regular income. Also independently associated with malnutrition was the inability to get more than two meals a day. In this context previous studies showed that reporting of two or less meals per day increased the likelihood of food insecurity among people living with HIV and AIDS (Semali et al., 2011). In this study, food insecurity was found to have significant association with under nutrition. Similar studies in Ethiopia and Nepal found that adult people HIV positive on ART or household with food insecurity had the highest odds of being undernourished (Thapa et al., 2015; Dedha et al., 2017).

Regarding CD4, there was a significant association between low CD4 counts with under nutrition. Patients who had CD4 count $<300$ cell $/ \mathrm{mm}^{3}$ were approximately five times more likely to be undernourished as compared to those with $\mathrm{CD} 4>300 \mathrm{cell} / \mathrm{mm}^{3}$. This is due to low immunity against infection. Similarly, the findings from Senegal and Ethiopia have also indicated that CD4 has significant effect on under nutrition (Benzekri et al., 2015; Mulu et al., 2016; Dedha et al., 2017). In contrary, a previous study in southern part of Ethiopia showed that CD4 counts has no significant effect on under nutrition (Hailemariam et al., 2013). The difference between the findings of the study reported here are probably due to variations in study population and period.

In conclusion, the prevalence of both under nutrition and severe malnutrition among PLHIV attending CTC in Temeke is still high. Furthermore, food insecurity, irregular income and having a CD4 count of less than 300 cells $/ \mathrm{mm}^{3}$ were positively associated with under nutrition. Therefore, efforts should be strengthened to alleviate the higher burden of under nutrition by considering the identified determinants. Assessment during follow-up and routine nutritional supplement therapy for under nutrition in conjunction with early start on ART need to be initiated. 


\section{References}

Benzekri, N.A., Sambou, J., Diaw, B., Sall, E.H., Sall, F., Niang, A., Ba, S., Guèye, N.F.N., Diallo, M.B., Hawes, S.E., Seydi, M. \& Gottlieb, G.S. (20150 High prevalence of severe food insecurity and malnutrition among HIV-infected adults in Senegal, West Africa. PLoS ONE 10:67-77.

Dannhauser, A., van Staden, A.M., van der Ryst, E., Nel, M., Marais, N., Erasmus, E., Attwood, E.M., Barnard, H.C. \& le Roux, G.D. (1999) Nutritional status of HIV-1 seropositive patients in the Free State Province of South Africa: anthropometric and dietary profiles. European Journal of Clinical Nutrition 53(3):165-173.

Folasire, O.F., Folasire, A.M. \& Sanusi, R.A. (2015) Measures of nutritional status and quality of life in adult people living with HIV/AIDS at a Tertiary Hospital in Nigeria. Food and Nutrition Sciences, 2015, 6, 412-420

Liu, E., Spiegelman, D.,Semu, H., Hawkins, C., Chalamilla, G., Aveika, A., Nyamsangia, S., Mehta, S., Mtasiwa, D. \& Fawzi, W. (2011) Nutritional Status and Mortality among HIV-infected Patients Receiving Antiretroviral Therapy in Tanzania. Journal of Infectious Diseases 204: 282-290.

Koethe, J.R. \& Heimburger, D.C. (2010) Nutritional Aspects of HIV-associated wasting in Sub-Saharan Africa. American Journal of Clinical Nutrition 91 (Suppl): 1138S -42S.

Koethe, J.R., Lukusa, A., Gigantti, M.J., Chi, B.H., Nyirenda, C.K., Limbada, M.I., Banda, Y., Stringer, J.S.A. (2010) Association between weight gain and clinical outcomes among malnourished adults on anti-retroviral therapy in Lusaka, Zambia. Journal of Acquired Immune Deficiency Syndrome 53:507-513

Kuria, E.N. (2010) Food consumption and nutritional status of people living with HIV/AIDS (PLWHA): a case of Thika and Bungoma Districts, Kenya. Public Health and Nutrition 13: 475-479.

MoHSW (2015) National Guidelines for Management of HIV and AIDS. NACP. Fifth Edition. May 2015 Ministry of Health, Community Development, Gender, Children and Elderly, Dar es Salaam, Tanzania.

Dedha, M., Damena, M., Egata, G. \& Negesa, L. (2017) Undernutrition and associated factors among adults human immunodeficiency virus positive on antiretroviral therapy in hospitals, East Hararge Zone, Oromia, Ethiopia. International Journal of Health Sciences 11: 35-42.

Mitiku, A., Ayele, T.A., Assefa, M. \& Tariku, A. (2016) Undernutrition and associated factors among adults living with Human Immune Deficiency Virus in Dembia District, northwest Ethiopia: an institution based cross-sectional study. Archives of Public Health74:33

Mulu, H., Hamza, L. \& Alemseged, F. (2016) Prevalence of malnutrition and associated factors among hospitalized patients with acquired immunodeficiency syndrome in Jimma University Specialized Hospital, Ethiopia. Ethiopian Journal of Health Sciences 26:217-226.

Niyongabo, T., Henzel, D., Ndayishimyie, J.M., Melchior, J.C., Ndayiragije, A., Ndihokubwayo, J.B., Nikoyagize, E., Rwasa, T., Aubry, P. \& Larouze, B. (1999) Nutritional status of adult Inpatients in Bujumbura hospitals, Burundi (impact of HIV infection). European Journal of Clinical Nutrition 53: 579-582.

Uthman, O. (2008) Prevalence and pattern of HIV-related Malnutrition among Women in sub Saharan Africa: a meta-analysis of Demographic and Health Surveys. BMC Public Health 8: 226.

Ritte, S.A. \& Kessy A.T. (2012) Food Consumption and nutritional status of people living with HIV/AIDS attending care and treatment clinics in Ilala District, Dar es Salaam. East African Journal of Public Health 9: 33-38.

Semali, I., Edwin, T. \& Mboera, L.E.G. (2011) Food insecurity and coping strategies among people living with HIV in Dar es Salaam, Tanzania. Tanzania Journal of Health Research 13: 259-267. 
Hailemariam, S., Bune, G.T. \& Ayele, H.T. (2013) Malnutrition: prevalence and its associated factors in people with HIV/AIDS, in Dilla University Referral Hospital. Archives of Public Health 71: 1-13.

THMIS (2013) Tanzania HIV and Malaria Indicator Survey, 2011-2012. Tanzania Commission for AIDS (TACAIDS), Zanzibar AIDS Commission (ZAC), National Bureau of Statistics Tanzania (2013).

Thapa, R., Amatya, A., Pahari, D.P., Bam, K. \& Newman, M.S. (2015) Nutritional status and its association with quality of life among people living with HIV attending public anti-retroviral therapy sites of Kathmandu Valley, Nepal. AIDS Research and Therapy 12:14.

WHO (2003) Nutritional Requirements for People Living with HIV/AIDS. Report of Technical Consultation. World Health Organization, Geneva, Switzerland. 